
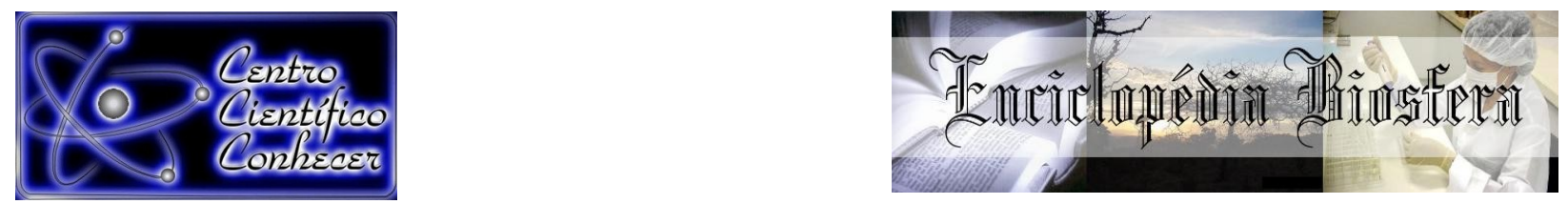

\title{
DETECÇÃO E ANÁLISE DA DISTRIBUIÇÃO DE FOCOS DE CALOR NO MUNICÍPIO DE IPIXUNA DO PARÁ - PA, NORDESTE PARAENSE
}

\author{
Patrick de Sousa Teixeira1; Milton Antônio da Silva Matta²
}

1Discente do Programa de Especialização em Gestão Hídrica e Ambiental da UFPA - Universidade Federal do Pará, Belém - PA, Brasil. E-mail: patrickteixeira@outlook.com

²Professor Doutor do Instituto de Geociências da Universidade Federal do Pará, Belém - PA, Brasil.

Recebido em: 15/11/2020 - Aprovado em: 15/12/2020 - Publicado em: 30/12/2020

DOI: 10.18677/EnciBio_2020D14

\begin{abstract}
RESUMO
O avanço da agropecuária na região Amazônica, em especial na Região Nordeste Paraense, aliado ao uso do fogo como principal técnica de preparação do solo e limpeza de pastagens, são fatores determinantes para o avanço do desmatamento da região. Neste sentido, o estudo buscou avaliar a disposição dos focos de calor no município de Ipixuna do Pará, através da ferramenta de estimativa de densidade de Kernel na modelagem temporal e espacial de dados de monitoramento por satélite. Foram utilizados dados, adquiridos a partir do Banco de Dados de Queimadas do Instituto Nacional de Pesquisas Espaciais - INPE, além de dados de precipitação pluviométrica, disponibilizados pela Agência Nacional de Águas - ANA, entre os anos de 2014 e 2019. Foi possível observar, durante a série temporal, um quantitativo total de 1.503 focos de calor, os quais estiveram concentrados sobretudo nas regiões central, norte e extremo sul do município, principalmente no interior das áreas de assentamentos de reforma agrária e pequenas propriedades rurais. Também foram identificados altos índices de densidade de focos de calor no interior da Terra Indígena Sarauá. Neste sentido, foi possível comprovar a influência do regime de chuvas no comportamento anual dos focos de calor, além do indicativo de interferência das práticas agrícolas com utilização do fogo para o crescimento do número de focos. Assim, a ferramenta de densidade de Kernel demonstrou capacidade para identificar a distribuição territorial dos focos de calor e a localidade, fornecendo material relevante para a realização de ações de combate a queimadas em todo território municipal.
\end{abstract}

PALAVRAS-CHAVE: Densidade de Kernel; Focos de Calor; Ipixuna do Pará; Monitoramento.

\section{DETECTION AND ANALYSIS OF THE DISTRIBUTION OF HEAT FOCI IN THE MUNICIPALITY OF IPIXUNA DO PARÁ - PA, NORTHEAST OF PARÁ}

\begin{abstract}
The advance of agriculture in the Amazon region, especially in the Northeast region of Pará, together with the use of fire as the main technique of soil preparation and pasture cleaning, are determining factors for the advance of deforestation in the region. In this sense, the study sought tovalue the disposition of heat foci in the municipality of Ipixuna do Pará, through the kernel density estimation tool in the ENCICLOPÉDIA BIOSFERA, Centro Científico Conhecer - Jandaia-GO, v.17 n.34; p. 185 2020
\end{abstract}


temporal and spatial modeling of satellite monitoring data. Datawere used, acquired from the Burn Database of the National Institute of Space Research - INPE, in addition to rainfalldata, made available by the National Water Agency - ANA,between 2014 and 2019. Itis possible to observe, during the time series, a total number of 1,503 heat foci, which were concentrated about everything mainly in the central, northern and extreme southern regions of the municipality, mainly within the areas of agrarian reform settlements and small rural properties. High rates of density of heat foci within the Sarauá Indigenous Land have also been identified. In this sense, it was possible to prove the influence of the rainfall regime on the annual behavior of heat foci,e in addition to the indication of the indication of agricultural practices with the use of fire for the growth of the number of foci. Thus, the Kernel density tool demonstrated the ability to identify the territorial distribution of heat foci to the locality,providing material relevant to the realization of actions to combat fires throughout the municipal territory..

KEYWORDS: Kernel Density; Hot Flashes; Monitoring; Ipixuna of Pará.

\section{INTRODUÇÃO}

A expansão da pecuária, a agricultura de corte e queima, a agricultura de larga escala e a extração madeireira, estão diretamente relacionadas ao aumento do desmatamento na Amazônia (RIVERO et al., 2009). De acordo com Fearnside (2009), os principais sistemas de produção aplicados ao bioma estão baseados na remoção da cobertura natural do solo e consequente depreciação dos recursos florestais.

Nesse sentido, as queimadas agrícolas apresentam-se como uma técnica antiga, utilizada por produtores rurais durante a preparação do solo para o manejo de pastagens visando a criação de bovinos, manejo do solo para o plantio de culturas e até a queima de resíduos domésticos (PEREIRA; SILVA, 2016). É um procedimento perigoso e que geralmente foge do controle, afetando grandes áreas e prejudicando fortemente as características de qualidade do solo, além de eliminar o hábitat natural de espécies endêmicas de fauna e flora e causar problemas respiratórios a população (PEREIRA; SILVA, 2016).

A emissão de gases do efeito estufa também é consequência deste processo. Segundo Sá et al. (2007), quase 75\% das emissões do País estão associadas ao uso do solo, queimadas e desmatamento, em especial na região Amazônica. Tais emissões têm efeito direto no desempenho do ecossistema amazônico e no clima regional e global (ARTAXO et al., 2014). De acordo com o Portal Terra Brasilis - INPE, em 2019, o Pará foi responsável por 41,63\% do total de áreas desmatadas na Amazônia, caracterizando-se como o Estado que mais contribuiu para o desmatamento do Bioma, neste ano (BRASIL, 2019). Destaca-se que a realização de queimadas sem a devida autorização do órgão ambiental competente é qualificada como crime contra o meio ambiente.

Nesse contexto, a região Nordeste Paraense, caracteriza-se pela antropização e relevante alteração da paisagem natural (BRASIL, 2006). A modificação do ambiente natural foi acelerada a partir da construção da BR-010 (Rodovia Belém-Brasília). Paralelo a isto, a extração madeireira e mineral, além do crescimento da atividade agropecuária foram determinantes para a mudança do cenário natural desta região (CORDEIRO; ARBAGE; SCHWARTZ, 2017).

O município de Ipixuna do Pará, inserido na região nordeste do Estado, apresenta relevante quantidade de focos de calor, os quais estão relacionados com a dinâmica de modificação do solo. Possui uma economia fundamentada sobretudo 
no desenvolvimento da pecuária e da agricultura familiar, sendo composto em boa parte, por assentamentos de reforma agrária e pequenas propriedades rurais (BRASIL, 2017).

Nesta perspectiva, os órgãos responsáveis pela gestão ambiental, promovem ações constantes de fiscalização e educação ambiental, mediante alertas dos sistemas de monitoramento e denúncias realizadas pela população. Assim, o uso de ferramentas geotecnológicas para a detecção das áreas de maiores índices de focos de calor podem auxiliar os órgãos de defesa ambiental na construção de programas de combate a incêndios florestais na região.

Deste modo, o objetivo principal deste trabalho foi detectar e avaliar a distribuição dos focos de calor, através da estimativa de densidade de Kernel, no Município de Ipixuna do Pará - PA, entre os anos de 2014 e 2019, por meio de dados de monitoramento por satélite.

\section{Caracterização da Área de Estudo}

\section{MATERIAL E MÉTODOS}

Este trabalho abordou a seguinte área de estudo: Município de Ipixuna do Pará (Figura 1), situado na região Nordeste Paraense, Região de Integração (RI) Rio Capim, as margens da BR 010, entre as coordenadas geográficas de latitude $06^{\circ} 04^{\prime} 03^{\prime \prime} \mathrm{S}$ e longitude $49^{\circ} 54^{\prime} 08^{\prime \prime} \mathrm{O}$, distante $250 \mathrm{~km}$ da capital Belém. A localidade possui área de $5.215,55 \mathrm{~km}^{2}$, ocupando cerca de $0,41 \%$ da área total do Estado. Ademais, apresenta densidade demográfica de $9,84 \mathrm{hab} . / \mathrm{km}^{2}$ (BRASIL, 2011), com população estimada de 65.625 pessoas (BRASIL, 2020c).

FIGURA 1. Mapa de localização da área de estudo.

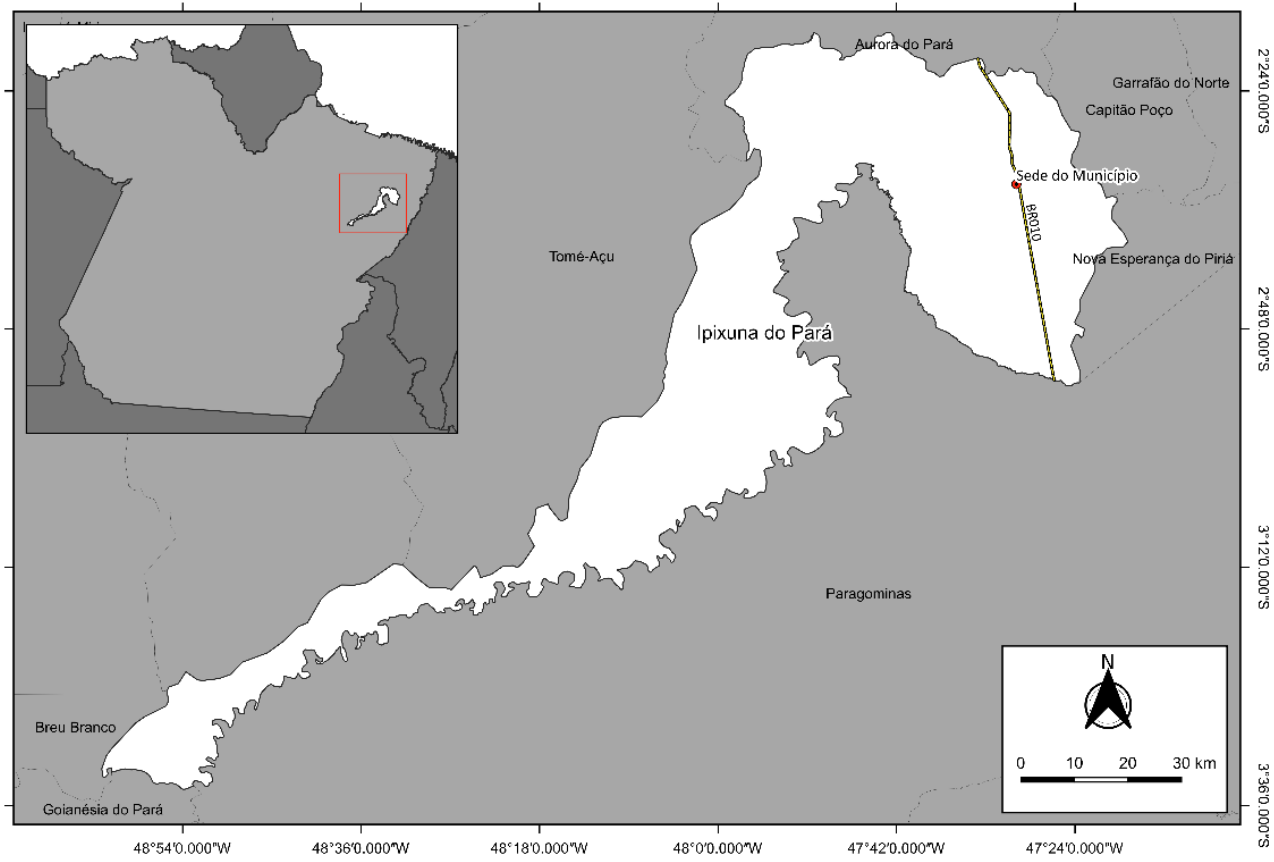

Fonte: BRASIL, (2015).

O Município caracteriza-se por um clima tropical com considerável regime de chuvas anuais. O clima é classificado como Am de acordo com a classificação de Koppen Geiger, com temperatura média de $26,7^{\circ} \mathrm{C}$ e pluviosidade média anual de 
$2.098 \mathrm{~mm}$. Possui dois períodos climáticos: Chuvoso, compreendido entre os meses de janeiro a maio e Seco, compreendido entre os meses de junho e dezembro.

Os solos predominantes em Ipixuna do Pará são classificados como: Latossolo Amarelo distrófico de texturas média, argilosa e muito argilosa e Plintossolo Pétrico Concrecionário, solos Aluviais e solos Hidromórficos indiscriminados nas áreas de várzea (BRASIL, 2006; BRASIL, 2008b). A tipologia de vegetação encontrada no município são as de floresta Ombrófila Densa de Terras Baixas e Floresta Ombrófila Densa Aluvial de diferentes idades (BRASIL, 2008a).

\section{Aquisição e Processamento de Dados}

$\mathrm{Na}$ pesquisa foram utilizados dados de focos de calor compreendidos no período entre os anos de 2014 e 2019 obtidos a partir do Banco de Dados de Queimadas disponibilizados pelo Instituto Nacional de Pesquisas Espaciais - INPE, através do Programa Queimadas em formato de armazenamento de dados de vetor do tipo shapefile (BRASIL, 2020d). Os dados são gerados a partir do processamento de imagens termais do Sensor MODIS (Moderate Resolution Imaging Spectroradiometer), que está a bordo do satélite de referência do INPE, AQUAUMD-Tarde. Já os dados de precipitação pluviométrica foram obtidos a através do portal HidroWeb, disponível no portal da Agência Nacional de Águas - ANA (BRASIL, 2020a).

As informações obtidas foram processadas através do software livre, de sistema de informações geográficas - SIG, QGIS, versão 3.10.2. Os shapefile de focos de calor foram compilados em uma base de dados única e sobrepostos a área de estudo para posterior manipulação e geração dos mapas de densidade de Kernel. A ferramenta de estimativa de Densidade de Kernel foi utilizada na criação dos mapas de distribuição de focos de calor, os quais também indicaram os pontos de maior concentração. As densidades de Kernel foram categorizadas em cinco classes distintas, denominadas: muito baixa, baixa, média, alta e muito alta. Os gráficos de ocorrência anual de precipitação e focos de calor foram elaborados através do software Microsoft-Excel 2016.

\section{RESULTADOS E DISCUSSÃO}

As análises realizadas a partir dos dados obtidos através do satélite AQUAUMD-Tarde, na fase temporal de seis anos, identificaram a ocorrência de 1.503 focos de calor. Percebeu-se um crescimento no número de focos de calor entre os anos de 2014 (339) a 2017 (344), com posterior queda a partir do ano de 2018, chegando ao menor índice do período em 2019, quando foram registrados um total de 124 focos de calor (Tabela 1).

TABELA 1. Total de focos de calor identificados pelo satélite AQUA-UMD-TARDE, INPE entre 2014 e 2019 em Ipixuna do Pará - PA.

\begin{tabular}{ccccccc}
\hline Mês/Ano & $\mathbf{2 0 1 4}$ & $\mathbf{2 0 1 5}$ & $\mathbf{2 0 1 6}$ & $\mathbf{2 0 1 7}$ & $\mathbf{2 0 1 8}$ & $\mathbf{2 0 1 9}$ \\
\hline janeiro & 6 & 4 & 17 & 2 & 6 & 4 \\
fevereiro & 1 & 2 & 5 & 0 & 0 & 0 \\
março & 0 & 0 & 0 & 0 & 2 & 0 \\
abril & 0 & 0 & 0 & 0 & 0 & 0 \\
maio & 0 & 0 & 3 & 1 & 0 & 1 \\
junho & 2 & 0 & 4 & 4 & 8 & 0 \\
julho & 5 & 12 & 5 & 39 & 15 & 12
\end{tabular}




\begin{tabular}{ccccccc} 
agosto & 28 & 17 & 16 & 24 & 17 & 10 \\
setembro & 17 & 20 & 13 & 8 & 14 & 7 \\
outubro & 84 & 48 & 21 & 41 & 20 & 19 \\
novembro & 84 & 149 & 135 & 135 & 58 & 42 \\
dezembro & 62 & 87 & 38 & 90 & 10 & 29 \\
\hline Total & $\mathbf{2 8 9}$ & $\mathbf{3 3 9}$ & $\mathbf{2 5 7}$ & $\mathbf{3 4 4}$ & $\mathbf{1 5 0}$ & $\mathbf{1 2 4}$ \\
\hline
\end{tabular}

Fonte: BRASIL, (2020d).

Neste contexto, do quantitativo total de focos de calor registrados, o ano de 2014 apontou 19,23\%, em 2015 foram registrados 22,55\%, em 2016 cerca de $17,1 \%$, em 2017 foram identificados 22,89\%, e durante os anos de 2018 e 2019 os percentuais de $9,98 \%$ e $8,25 \%$, respectivamente. Lopes et al. (2017) ao realizarem uma análise da distribuição de focos de calor no município de Novo Progresso, Sudoeste Paraense, entre os anos de 2010 a 2015, constataram um total de 8.034 focos de calor, distribuídos ao longo dos $38.162 \mathrm{~km}^{2}$ de área total, com maiores índices evidenciados durante o período de estiagem das chuvas.

O aumento do número de focos de calor em Ipixuna do Pará, entre os anos de 2014, 2015, 2016 e 2017, notados a partir do gráfico do comportamento anual de focos de calor (Figura 2), pode estar atrelado ao avanço do desmatamento ilegal. Conforme informações obtidas a partir do PRODES, do Instituto Nacional de Pesquisas Espaciais - INPE, o município possuía até 2017, cerca de 52.88\% $\left(2.773,4 \mathrm{~km}^{2}\right)$ do território desmatado (BRASIL, 2019).

FIGURA 2. Comportamento anual de focos de calor, entre os anos de 2014 e 2019, no município de Ipixuna do Pará - PA.

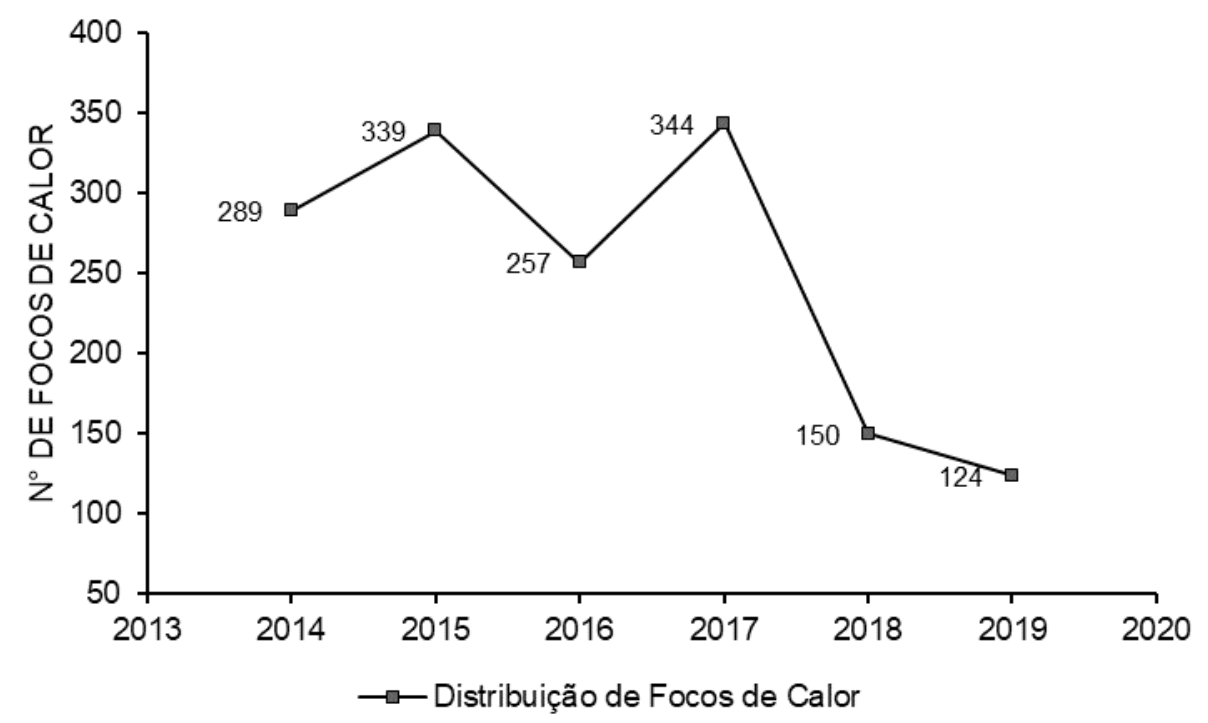

Fonte: BRASIL, (2020d).

Nesse cenário, é válido frisar que a agricultura tradicional de corte e queima é uma das formas de manejo mais utilizadas na região nordeste paraense, onde está localizado o município de Ipixuna do Pará, e que o período mais propício para uso do fogo, como método de preparação do solo, é o período de estiagem das chuvas (SAMPAIO et al., 2017). Outrossim, conforme a Fundação Amazônia de Amparo e Pesquisas do Pará - FAPESPA, em 2017, Ipixuna do Pará ocupou a 54 posição entre os municípios produtores de rebanho bovino no estado do Pará, com 
uma produção total de 95.104 cabeças de gado (PARÁ, 2019). Estes dados indicam uma necessidade de abertura de amplas áreas para produção além da prática do uso do fogo como técnica de limpeza de pastos.

No entanto, é importante evidenciar que o município manteve, entre o período analisado nesta pesquisa, a taxa anual de desmatamento abaixo dos 40 $\mathrm{km}^{2}$, meta estabelecida pelo Programa Municípios Verdes do Estado do Pará, o qual o município faz parte desde o ano de 2011. Além disso, Ipixuna do Pará não se encontra na lista dos municípios que mais desmatam na Amazônia do Ministério do Meio Ambiente - MMA (BRASIL, 2013).

A Figura 3 indica o comportamento mensal da incidência de focos de calor diante do regime pluviométrico em cada um dos anos avaliados. Constatou-se, que a distribuição anual de focos de calor possui relação direta com regime de chuvas da região, exibindo um padrão de distribuição estabelecido no decorrer dos meses avaliados, com maior incidência de focos de calor entre o período de escassez de chuvas (julho a dezembro), possuindo maiores picos durante o mês de novembro, e demonstrando queda na quantidade de focos nos meses com maiores precipitações.

FIGURA 3. Comportamento mensal da incidência de focos de calor diante do regime pluviométrico anual no município de Ipixuna do Pará - PA.
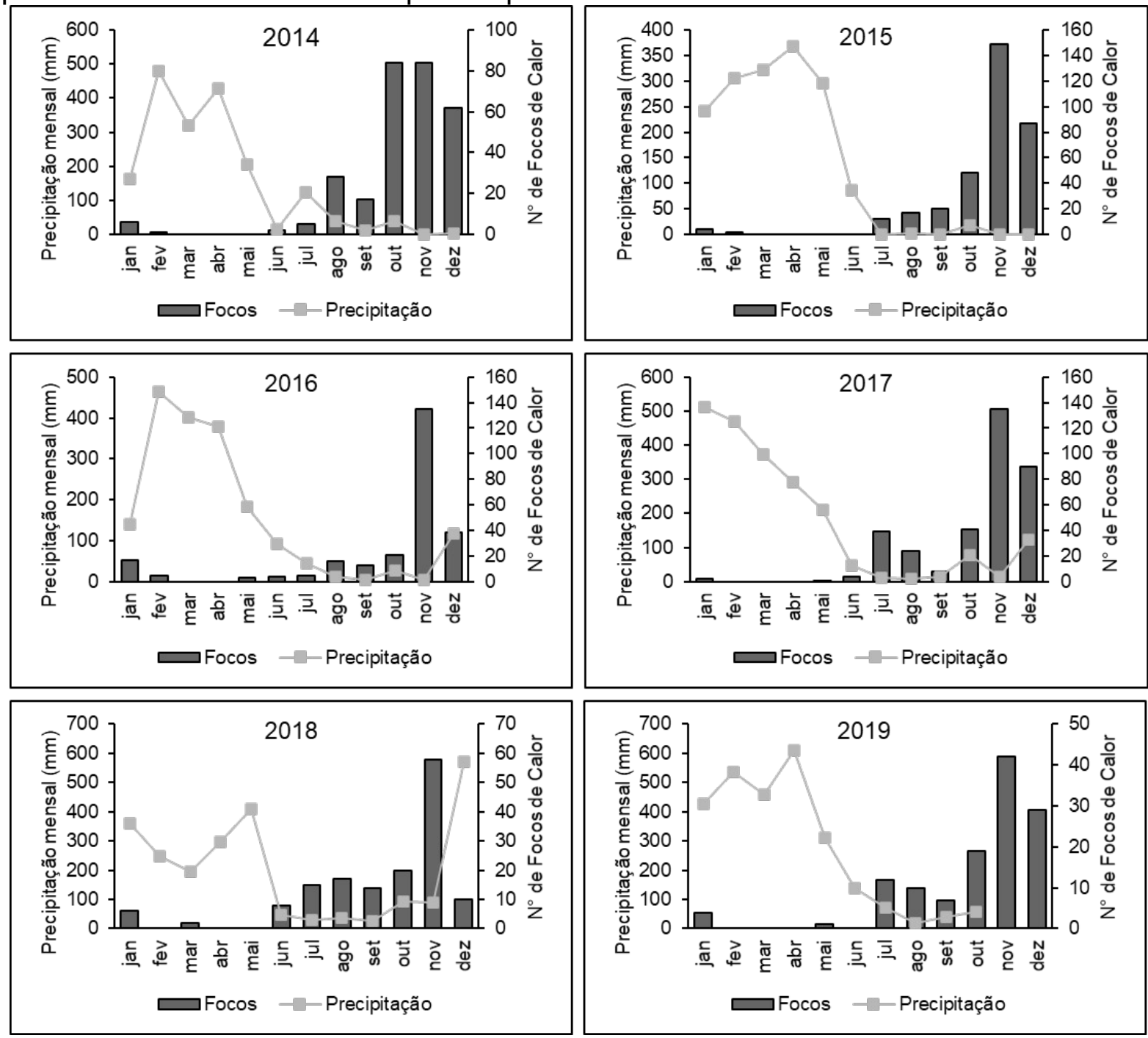

Fonte: BRASIL, (2020a); BRASIL, (2020d). 
Deste modo, ressalta-se que a microrregião de Ipixuna do Pará possui duas estações climáticas bem definidas, sendo: o período chuvoso ocorrendo entre os meses de janeiro a maio e o período de estiagem, compreendido entre os meses de junho e dezembro. Também é importante salientar que, entre os anos de 2015 e 2016, ocorreu a intensificação do fenômeno climático El Niño, o qual provoca uma diminuição no regime de chuvas, tornando o ambiente mais seco e mais propício para a realização de queimadas (MOREIRA et al., 2018). Tais fatores ajudam a compreender o comportamento de crescimento da incidência de focos de calor a partir do mês de julho, mantendo o crescimento até dezembro. Destaca-se a elevação atípica do regime de chuvas durante o mês de dezembro de 2018, que pode ter auxiliado na diminuição da quantidade de focos para este mês. Também é importante que a série temporal de regime pluviométrico do ano de 2019 , não ofereceu dados para os meses de novembro e dezembro.

Fernandes et al., (2018), realizando uma análise na microrregião de Parauapebas, entre os anos de 2011 e 2016, reconheceram a existência de relação entre a precipitação e o aumento do risco de queimadas, a partir da identificação do crescimento do número de focos entre os meses de julho a outubro e dos baixos índices pluviométricos durante o mesmo período. Santos et al., (2020), analisando a detecção de focos de calor no Estado do Pará, nos anos de 2005, 2010 e 2015, também constataram que a redução dos índices pluviométricos juntamente com o aumento da temperatura, facilitam a ocorrência de queimadas, contudo, ressaltam que estes fatores não são determinantes.

Os mapas de Kernel, apresentados na Figura 4, indicam dispersão de focos de calor em toda área de estudo, classificando as densidades em cinco classes: Muito Baixa, Baixa, Média, Alta e Muito Alta. Desta forma, os anos de 2014, 2015, 2016 e 2017 foram os que mais sistematizaram altos índices de focos de calor, com concentrações das classes Média, Alta e Muito Alta. Destacou-se a presença de altas concentrações de focos, principalmente das classes Média, Alta e Muito Alta, no extremo sul, centro e norte do município, principalmente durante o ano de 2017.

FIGURA 4. Análise espacial de focos de calor, identificados pelo satélite AQUAUMD-TARDE, entre os anos de 2014 e 2019, no município de Ipixuna do Pará.

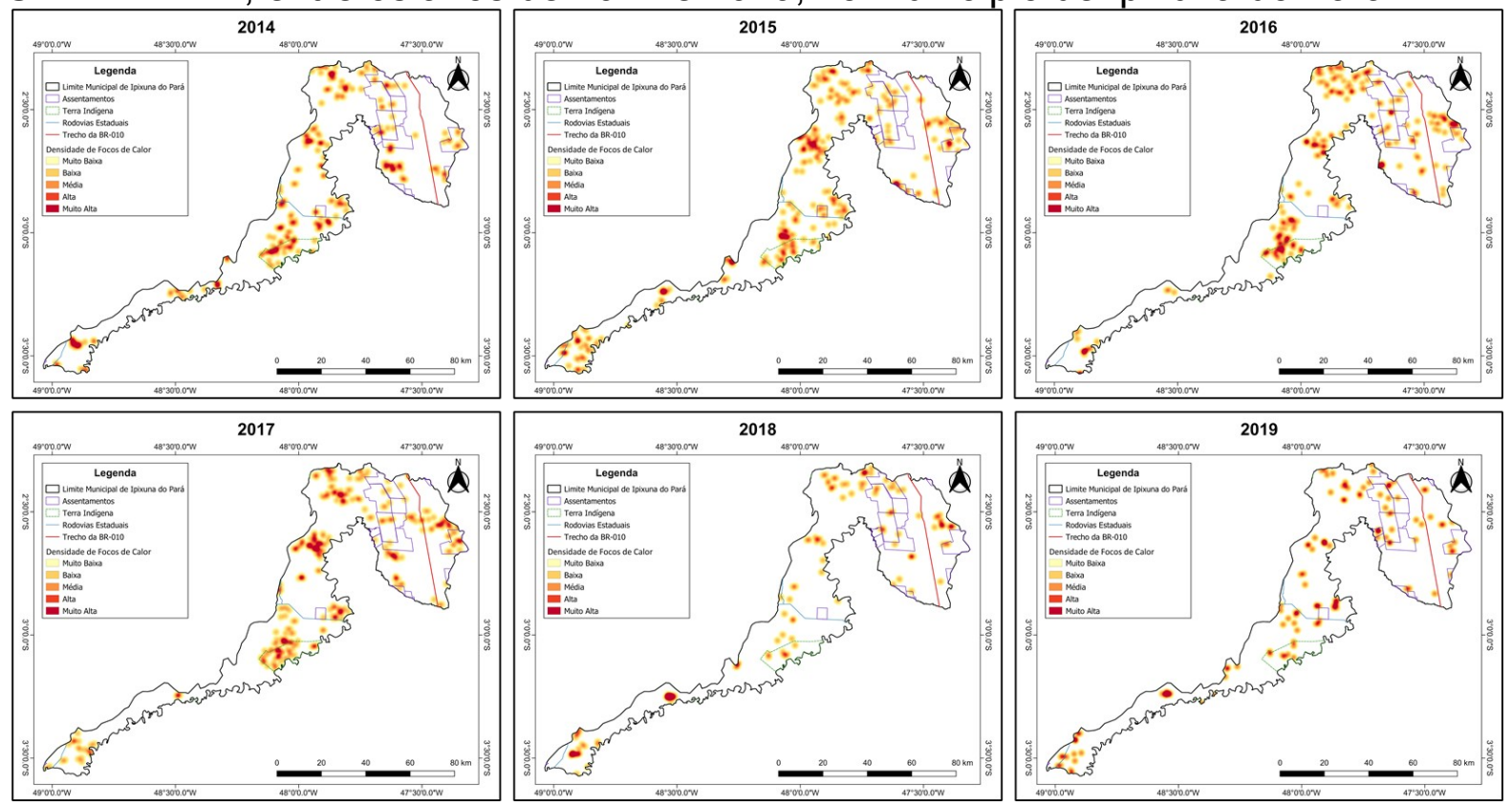

Fonte: BRASIL, (2020d). 
É relevante evidenciar que a parte Norte do Município concentra grande parte das áreas de assentamentos estaduais de reforma agrária presentes em Ipixuna do Pará e que em todo período de estudo, foram identificados focos de calor concentrados no interior dessas áreas, principalmente nos assentamentos denominados Candiru, União e Minas Pará. Segundo Sales et al. (2019), em pesquisa relacionada a utilização de focos de calor na avaliação de queimadas e em incêndios florestais, no município de Paragominas - PA, foram registrados durante $o$ ano de 2016, uma quantidade significativa de focos de calor em áreas de Projetos de Assentamentos Agrícolas. Tais ocorrências estariam relacionadas principalmente a realização de práticas tradicionais de preparo do solo com a utilização do fogo.

Rocha et al., (2020), também identificaram focos de calor ocorridos nos limites de um assentamento localizado entre os municípios de Rio Branco e Senador Guiomard no Estado do Acre, entre os anos de 2010 a 2019. Ainda no Estado do Acre, entre os anos de 2001 e 2014, Anderson et al., (2017) registraram que $39 \%$ do total de focos de focos de calor existentes em todo o Estado neste período, estavam localizados em áreas de projetos de assentamentos, demonstrando a forte presença do uso do fogo nestas áreas. Ainda neste sentido, Santos et al. (2018), analisando as principais técnicas do uso do fogo por agricultores familiares residentes em assentamentos no município de Novo Progresso, PA, apontaram que $86 \%$ dos agricultores entrevistados, fazem uso do fogo na agricultura.

Também foi possível observar, a partir da sobreposição com ShapeFiles da base de referência do Sistema Nacional de Cadastro Ambiental Rural - SICAR, que as principais ocorrências de intensificação das classes de densidade de focos de calor do tipo Média, Alta e Muito Alta ocorreram nas regiões onde há a predominância de pequenas propriedades rurais (imóveis com área entre um a quatro módulos fiscais). A comunidade rural Balalaica, localizada na parte central da área de estudo, está entre as regiões de pequenos proprietários de terra que apresentou altas densidades de focos de calor.

A Terra Indígena Sarauá, de aproximadamente 19 mil ha, está localizada próximo a esta comunidade rural e também apresentou em seu território, densidade de focos de calor das classes Alta e Muito Alta. Ao todo foram contabilizados 151 focos de calor, dentro deste Território Indígena, durante o período estudado. Tal comportamento revela um avanço das queimadas sobre estas áreas tradicionalmente ocupadas, protegidas a partir do art. 231 da Constituição Federal de 1988 e demarcadas através do Decreto n. ${ }^{0}$ 1.775/96 (BRASIL, 1988; BRASIL, 1996).

Já entre os anos de 2018 e 2019, a concentração de focos de calor apresentou queda considerável, sendo visível a redução das classes Alta e Muito alta na região Central e Norte do território estudado. No entanto, foi possível observar a permanência das densidades Alta e Muito Alta em áreas próximas a rodovias estaduais a ao trecho da BR-010. Milien e Rocha (2020), em análise realizada no entorno da rodovia BR-17, no estado do Acre, entre os anos de 2001 a 2017, identificaram um aumento do desmatamento em áreas localizadas próximas a rodovia, em decorrência de atividades antrópicas e do desenvolvimento da pecuária no estado. 


\section{CONCLUSÃO}

Foram registrados um total de 1.503 focos de calor distribuídos principalmente nas regiões Norte, Sul e Central do Município, com destaque para a presença de altas concentrações de focos de calor na Terra Indígena Sarauá, em áreas de assentamentos agrícolas e sobretudo em comunidades com a predominância de pequenas propriedades rurais, principalmente entre os anos de 2014 e 2017.

A variação anual relevou que a maior quantidade de focos esteve presente durante os meses de outubro, novembro e dezembro, período de estiagem das chuvas, reafirmando a influência do regime pluviométrico no favorecimento do acréscimo e decréscimo dos números de focos de calor na região. No entanto, a utilização do fogo durante a limpeza de pastos e como técnica de preparo do solo, utilizada principalmente pelo pequeno produtor, se apresentam como principal causas da incidência de queimadas na região.

De modo geral, os resultados obtidos indicaram a eficiência do estimador de Densidade de Kernel na identificação das maiores incidências de focos de calor no Município de Ipixuna do Pará - PA, durante os anos analisados. A ferramenta demonstrou potencial para o reconhecimento de pontos críticos de ocorrências de focos de calor e forneceu subsídios para a realização do monitoramento, fiscalização e conscientização ambiental.

\section{REFERÊNCIAS}

ANDERSON, L. O.; YAMAMOTO, M.; CUNNINGHAM, C.; FONSECA, M. G.; FERNANDES, L. K. et al. Utilização de dados orbitais de focos de calor para caracterização de riscos de incêndios florestais e priorização de áreas para a tomada de decisão. Revista Brasileira de Cartografia. Monte Carmelo, MG, v. 69, n. $1, \quad$ jan. 2017, p. 163-177. Disponível em: <http://www.seer.ufu.br/index.php/revistabrasileiracartografia/article/view/44038>. Acesso em: 27 de junho de 2020.

ARTAXO, P.; DIAS, M. A. F. S.; NAGY, L.; LUIZÃO, F. J.; CUNHA, H. B. et al. Perspectivas de pesquisas na relação entre clima e o funcionamento da floresta Amazônica. Ciência e Cultura [online]. São Paulo, v. 66, n. 3, p. 41-46, set/2014. Disponível em: <http://dx.doi.org/10.21800/S0009-67252014000300014>. Acesso em: 15 de abril de 2020.

BRASIL, Agência Nacional de Águas. Portal HidroWeb. 2020a. Disponível em: <http://www.snirh.gov.br/hidroweb/serieshistoricas>. Acesso em: 30 de julho de 2020.

BRASIL, Instituto Nacional de Geografia e Estatística. Mapas: Bases e referenciais. 2015. Disponível em: <https://mapas.ibge.gov.br/bases-e-referenciais/ bases-cartograficas/malhas-digitais.html>. Acesso em: 20 de abril de 2020.

BRASIL, Instituto Nacional de Geografia e Estatística. Área Territorial Brasileira. Rio de Janeiro, RJ, 2020b. Disponível em: $<$ https://cidades.ibge.gov.br/brasil/pa/ipixuna-do-para/panorama>. Acesso em: 13 de abril de 2020. 
BRASIL, Instituto Nacional de Geografia e Estatística. Censo Agropecuário 2017 Resultados definitivos. $2017 . \quad$ Disponível em: $<$ https://cidades.ibge.gov.br/brasil/pa/ipixuna-do-para/pesquisa/24/76693>. Acesso em: 15 de abril de 2020.

BRASIL, Instituto Nacional de Geografia e Estatística. Censo Demográfico 2010, área territorial brasileira. Rio de Janeiro, 2011. Disponível em: <https://cidades.ibge.gov.br/brasil/pa/ipixuna-do-para/panorama>. Acesso em: 14 de abril de 2020.

BRASIL, Instituto Nacional de Geografia e Estatística. Estimativas da população residente para os municípios e para as Unidades da Federação brasileiros com data de referência em $1^{\circ}$ de julho de 2020. 2020c. <Disponível em: https://www.ibge.gov.br/estatisticas/sociais/populacao/9103-estimativas-depopulacao.html?=\&t=resultados $>$. Acesso em: 15 de abril de 2020.

BRASIL, Instituto Nacional de Geografia e Estatística. Mapa de Cobertura Vegetal, Estado do Pará. $1^{a}$ ed. Rio de Janeiro. 2008a. Projeção Policônica. Datum horizontal SIRGAS 2000. Escala: 1:800.000. Disponível em: <https://www.ibge.gov.br/geociencias/informacoes-ambientais/vegetacao/22460vegetacao-por-estado.html?=\&t=downloads $>$. Acesso em: 14 de abril de 2020.

BRASIL, Instituto Nacional de Geografia e Estatística. Mapa Esquemático de Solos, Estado do Pará. $1^{a}$ ed. Rio de Janeiro. 2008b. Projeção Policônica. Datum horizontal SIRGAS 2000. Escala: 1:800.000. Disponível em: <https://mapas.ibge.gov.br/tematicos/solos>. Acesso em: 14 de abril de 2020.

BRASIL, Instituto Nacional de Pesquisas Espaciais. 2019. Portal TerraBrasilis, PRODES. em: <http://terrabrasilis.dpi.inpe.br/app/dashboard/deforestation/biomes/amazon/ increments. >. Acesso em: 17 de abril de 2020.

BRASIL, Instituto Nacional de Pesquisas Espaciais. Banco de Dados de Queimadas. 2020d. Disponível em: $<$ http://queimadas.dgi.inpe.br/queimadas/bdqueimadas/\#>. Acesso em: 16 de abril de 2020.

BRASIL, Lei Federal n. 1.775/1996, de 08 de janeiro de 1996. Presidência da República, Subchefia para Assuntos Jurídicos, 1996. Disponível em: < http://www.planalto.gov.br/ccivil_03/decreto/D1775.htm>. Acesso em: 30 de julho de 2020.

BRASIL, Ministério do Desenvolvimento Agrário (MDA); Secretaria De Desenvolvimento Territorial (SDT) \& Fundação Sócio-Ambiental do Nordeste Paraense (FANEP). Diagnóstico e Planejamento de Desenvolvimento do Território Rural do Nordeste Paraense. Capanema, PA. 2006. Disponível em: <http://sit.mda.gov.br/download/ptdrs/ptdrs_territorio061.pdf>. Acesso em: $10 \mathrm{de}$ abril de 2020. 
BRASIL, Ministério do Meio Ambiente - MMA. Lista de Municípios Prioritários da Amazônia. $2013 . \quad$ Disponível em: <https://www.mma.gov.br/images/arquivos/florestas/controle_e_prevencao/2014/ lista_\%20municipios_\%20prioritarios_07.08.pdf>. Acesso em: 18 de abril de 2020.

CORDEIRO, I. M. C. C.; ARBAGE, M. J. C.; SCHWARTZ, G. Nordeste do Pará: configuração atual e aspectos identitários. In: CORDEIRO, I. M. C. C.; RANGELVASCONCELOS, L. G. T.; SCHWARTZ, G.; OLIVEIRA, F. de A. (Org.). Nordeste Paraense: panorama geral e uso sustentável das florestas secundárias. Belém, PA: EDUFRA, 2017. Cap. I, p. 19-58. Disponível em: <http://ainfo.cnptia.embrapa.br/digital/bitstream/item/162426/1/Livro-Nordeste.pdf>. Acesso em: 29 de julho de 2020.

FEARNSIDE, P. M. A floresta amazônica nas mudanças globais. Editora INPA. Manaus, AM, 2009, $2^{\mathrm{a}}$ ed. $134 \quad$ p.: il. Disponível em: < http://philip.inpa.gov.br/publ_livres/LISTAS\%20POR\%20ASSUNTO-L.htm\#Mudan \%C3\%A7as_Clim\%C3\%A1ticas>. Acesso em: 16 de abril de 2020.

FERNANDES, T.; HACON, S. S.; NOVAIS, J. W. Z.; SOUSA, I. P.; FERNANDES, T. Detecção e análise de focos de calor no município de Parauapebas-PA, Brasil, por meio da aplicação de geotecnologia. Enciclopédia Biosfera, Centro Científico Conhecer, Goiânia, GO, v.15, n.28, 2018, 398 p. Disponível em: $<$ https://www.conhecer.org.br/enciclop/2018B/AGRAR/deteccao\%20e $\% 20$ analise.pdf $>$. Acesso em: 20 de abril de 2020.

LOPES, A. C. L.; FREITAS, A. V. M.; COSTA, D. O.; BELTRÃO, N. E. S.; TAVARES, $P$. A. Análise da distribuição de focos de calor no município de Novo Progresso, Pará. Revista Verde, Pombal, PB, v. 12, n. 2, p. 298-303, abr./jun. 2017. Disponível em: <http://dx.doi.org/10.18378/rvads.v12i2.4843>. Acesso em: 19 de abril de 2020.

MILIEN, E. J.; ROCHA, K. S. Análise do Desmatamento no entorno da Rodovia Br317 entre Assis Brasil e Xapuri no Acre. In: Impacto, excelência e produtividade das ciências agrárias no Brasil [recurso eletrônico], SILVA, R. R. S. S.; MATOS, H. A. F. A., CORDEIRO, K. V. C. Ponta Grossa, PR: Atena, p. 16-27, 2020. Disponível em: $<10.22533 /$ at.ed.7512002042>. Acesso em: 01 de agosto de 2020.

MOREIRA, S. F.; CONCEIÇÃO, C. S.; CRUZ, M. C. S.; JUNIOR, A. P. A Influência dos fenômenos El Niño e La Niña sobre a dinâmica climática da região Amazônica. Multidisciplinary Reviews. v. 1. n. 1, p. 1-7, 2018. Disponível em: $<10.29327 /$ multi.2018014>. Acesso em: 29 de julho de 2020.

PARÁ. Fundação Amazônia de Amparo a Estudos e Pesquisas - FAPESPA. Anuário Estatístico do Pará 2019. 2019. Disponível em: <http://www.fapespa.pa.gov.br/menu/163>. Acesso em: 17 de abril de 2020.

PEREIRA, J. A. V.; SILVA, J. B. Detecção de focos de calor no Estado da Paraíba: um estudo sobre as queimadas. Revista Geográfica Acadêmica, Boa Vista, RR, v.10, n.1, viii., 2016. Disponível em: <https://revista.ufrr.br/rga/article/view/3173>. Acesso em: 11 de abril de 2020. 
RIVERO, S.; ALMEIDA, O.; ÁVILA, S.; OLIVEIRA, W. Pecuária e desmatamento: uma análise das principais causas diretas do desmatamento na Amazônia. Nova Economia. Belo Horizonte, MG, v. 19, n. 1, P.41-66, abr. 2009. Disponível em: <https://doi.org/10.1590/S0103-63512009000100003>. Acesso em 05 maio 2020.

ROCHA, K. S.; ARAÚJO, A. A.; DUETI, L. S. M. Focos de calor no sudoeste da Amazônia: indicador do efeito da Ação Civil Pública - ACP do "fogo zero". Brazilian Journal of Development. Curitiba, PR, v. 6, n. 5, p. 30597-30609, mai. 2020. Disponível em: <https://doi.org/10.34117/bjdv6n5-499>. Acesso em: 20 de jun. de 2020.

SÁ, T. D. A.; KATO, O. R.; CARVALHO, C. J. R; FIGUEIREDO, R. O. Queimar ou não queimar? De como produzir na Amazônia sem queimar. Revista USP, São Paulo, SP, n.72, p. 90-97, dez. - fev., 2006-2007, Disponível em: <http://www.revistas.usp.br/revusp/article/view/13572/15390>. Acesso em: 20 de abril de 2020.

SALES, G. M.; PEREIRA, J. L. G.; THALÊS, M. C.; POCCARD-CHAPUIS, R.; ALMEIDA, A. S. Emprego dos focos de calor na avaliação das áreas queimadas e em incêndios florestais em Paragominas, Pará, Brasil. Boletim do Museu Paraense Emílio Goeldi. Ciências Naturais. v.14, n.1, p. 55-77, 2019. Disponível em: <https:// boletimcn.museu-goeldi.br/bcnaturais/article/view/140>. Acesso em: 13 de abril de 2020.

SAMPAIO, S. M. N.; VENTURIERI, A.; CAMPOS, A. G. S.; ELLERES, F. A. P. Dinâmica da cobertura vegetal e do uso da terra na mesorregião Nordeste paraense. In: CORDEIRO, I. M. C. C.; RANGEL-VASCONCELOS, L. G. T.; SCHWARTZ, G.; OLIVEIRA, F. de A. (Org.). Nordeste Paraense: panorama geral e uso sustentável das florestas secundárias. Belém, PA: EDUFRA, 2017. Cap. IV, p. 131-159. Disponível em: <http://ainfo.cnptia.embrapa.br/digital/bitstream/item/162426/1/Livro-Nordeste.pdf>. Acesso em: 29 de julho de 2020.

SANTOS, J. A. C. S.; PAULETTO, D.; MOTA, C. G.; SILVA, S. U. P.; NASCIMENTO, G. C. S. et al. Uso do fogo na agricultura: medidas preventivas e queima controlada no projeto de desenvolvimento sustentável terra nossa, Novo Progresso, Pará. Revista Agroecossistemas. v. 10, n. 2, p. 353-366, 2018. Disponível em: < http://dx.doi.org/10.18542/ragros.v10i2.5211>. Acesso em: 30 de julho de 2020.

SANTOS, K.; SILVA, D.; GUIMARÃES, R. Análise Multitemporal de focos de queimadas e variáveis climáticas, no Estado do Pará. Revista Geografia Acadêmica. Boa Vista, RR, v.14, n.1, vii., p. 118-133, 2020. Disponível em: <https://revista.ufrr.br/rga/article/view/6228>. Acesso em: 29 de julho de 2020. 